Review

\title{
An updated review on the epidemiology, pathophysiology, etiology, and diagnosis of liver cirrhosis
}

\author{
Gee Young Geong ${ }^{1, *}$, Sun Hyung Kang ${ }^{2}$ and Chang Min Lee ${ }^{3}$ \\ 1 Liver Research Institute, Seoul National University College of Medicine, Seoul, Korea ; \\ geegeong63@gmail.com \\ 2 Department of Internal Medicine, Seoul National University Bundang Hospital, Seongnam, Korea ; \\ zhang95da@outlook.com \\ 3 Department of Internal Medicine, Seoul National University Bundang Hospital, Seongnam, Korea ; \\ changminlee54@outlook.com \\ * Correspondence: geegeong63@gmail.com; Tel.: 82-2-2072-0505
}

\begin{abstract}
Liver cirrhosis is a chronic disease that is characterized by the presence of fibrosis and regeneration of nodules in the liver whose consequences are the development of portal hypertension and liver failure. Cirrhosis arises from a wide variety of chronic diseases, which progresses slowly after years or decades. Liver cirrhosis is a public health problem. It is usually associated with viral hepatitis, consumption of alcohol, metabolic syndrome, autoimmune processes, storage diseases, toxic substances, and medications. Cirrhosis is the fourteenth most common cause of death in adults throughout the world, the fourth in Europe and the ninth in the United States. The prevalence of this disease is underestimated because it is symptomatic it is not diagnosed in initial stages, and it usually goes to the decompensated stage at a rate of 5 to $7 \%$ per year. We review here the epidemiology, pathophysiology, etiology, and diagnosis of liver cirrhosis.
\end{abstract}

Keywords: Liver cirrhosis; epidemiology; etiology; risk factors; pathophysiology; diagnosis.

\section{Introduction}

Liver cirrhosis is a chronic disease that is characterized by the presence of fibrosis and regeneration of nodules in the liver whose consequences are the development of portal hypertension and liver failure [1].

Cirrhosis arises from a wide variety of chronic diseases, which progresses slowly after years or decades. It may arise as a consequence of an exogenous toxic, infectious, autoimmune, vascular process, by deposition or an error of innate metabolism. Patients are primarily diagnosed when they are identified with alterations of the anatomy and liver function through clinical examination, biochemical tests, imaging and/or histological findings [2].

This disease is a worldwide problem and is not isolated from other chronic pathologies such as obesity, diabetes, and heart disease [3]. It affects all ethnic groups, ages, sex and is the cause of a high rate of medical consultations, hospital admissions, health expenses and morbidity and mortality [4].

Liver cirrhosis is a public health problem [5]. It is usually associated with transmissible infectious diseases such as viral hepatitis, consumption of alcohol, metabolic syndrome, autoimmune processes, storage diseases, toxic substances and medications [6]. It is known that up to $40 \%$ of patients remain asymptomatic for long periods; however, once the complications develop, a progressive deterioration occurs whose outcome is death if the patient undergoes a definitive treatment that is the liver transplant [7]. Many patients die of the disease in their fifth or sixth decade of life [6]. 
Cirrhosis causes an enormous burden on the economy of health. We have data from the United States indicating that this pathology is responsible for 150,000 hospitalizations per year and causes an annual cost of 4 billion dollars. In Europe, costs may be up to 664.77 euros per patient each month because of this disease [8,9]. Cirrhosis is the fourteenth most common cause of death in adults throughout the world, the fourth in Europe and the ninth in the United States. It causes 1.3 million deaths per year throughout the world $[10,11]$.

The main etiologies of cirrhosis in the most developed countries are infection with the hepatitis $\mathrm{C}$ virus, alcohol abuse, and nonalcoholic steatohepatitis. Other causes include autoimmune hepatitis, Hepatitis B, primary sclerosing cholangitis, primary biliary cirrhosis, medications. Once a complication of cirrhosis develops, the rate of survival at 5 years decreases to less than $20 \%[12,13]$.

The main complications include gastrointestinal variceal hemorrhage, ascites, spontaneous bacterial peritonitis infection, hepatorenal syndrome, hepatic encephalopathy, and hepatocellular carcinoma [6,14]. Ascites is one of the most common complications of cirrhosis and is associated with a rate of mortality per year of $20 \%$ [15-17]. Infections cause $30 \%$ mortality in one month and another $30 \%$ within one year. The most frequent diagnoses are spontaneous bacterial peritonitis, urinary tract infections, pneumonia and skin infections [18,19]. Esophageal varices occur in 30 to $70 \%$ of patients with cirrhosis, with the risk of bleeding being about $12 \%$ per year [20]. When hemorrhage occurs, it may be fatal with a mortality rate of at least $20 \%$ at 6 weeks $[17,21]$. The development of hepatic encephalopathy is an ominous sign in cirrhosis since the mortality rate associated with it is up to $64 \%$ in a year [22]. Another complication is hepatocellular carcinoma, which is diagnosed in more than $70 \%$ of cases as an unresectable tumor [23]. The survival rate without treatment per year is $29 \%$ [24].

\section{Epidemiology}

Liver cirrhosis is a chronic disease present worldwide, which has no distinction by sex or ethnicity, distributed irregularly throughout the planet [25]. It is the 14th most common cause of death in adults worldwide, the fourth in Europe and the ninth in the United States. It causes 1.3 million deaths per year world level [26,27]. According to data from the World Health Organization in 2018, it is the ninth cause of death in low middle-income countries [28]. The prevalence of this disease is underestimated because it is symptomatic it is not diagnosed in initial stages, and it usually goes to the decompensated stage at a rate of 5 to $7 \%$ per year [29].

\section{Physiopathology}

Liver cirrhosis has several etiologies that ultimately lead to the same process that is hepatic fibrosis that leads to impaired function. According to stimuli, the damage can be faster or slower; for example, alcohol and viral hepatitis produce damage earlier. Progression degeneration of hepatocytes occurs and leads to necrosis, and an extracellular fibrotic scar material is formed to replace the parenchyma with regeneration nodules [1,30].

The process of fibrosis is dynamic, and the early stages can be reversible, but despite new studies, it has not been possible to conclude at what point this process becomes irreversible or create a drug that stops this progression [31]. It is considered that the main mechanism for the initiation of fibrosis is the activation of the hepatic stellate cell; this occurs in two phases. The first called initiation or pre-inflammatory is produced by bodies formed from cellular apoptosis, oxidative stress, stimuli from Kupffer cells, hepatocytes, platelets, and the endothelium. Then a perpetuation phase begins where there is cell proliferation and fibrogenesis with an important inflammatory response [32].

There is a degradation of the extracellular matrix by the action of metalloproteinases, which are produced mainly by stellate cells, when there is an imbalance between production and 
degradation, then the fabric begins to be replaced by fibrosis. It is believed that the reabsorption of this excess degraded matrix could reverse the liver alteration and therefore is the goal of the search for new treatments [33,34].

\section{Etiology}

\subsection{Alcohol use}

The liver is the primary target organ of ethanol damage because here the majority of the metabolism occurs. Excessive alcohol consumption causes three types of chronic liver disease such as steatosis (fatty liver), steatohepatitis, fibrosis and cirrhosis [35,36]. Alcohol is one of the leading causes of liver cirrhosis and hepatic transplantation in the world [37]. In the United States, of the total number of patients with the disease, $40 \%$ were alcoholics. $20 \%$ of the drinkers who ingest $40-80$ $\mathrm{g} /$ day in males and 20-40 g/day in women will develop this pathology within 10 to 12 years. In alcoholics, other factors intervene in liver damage such as genetic predisposition, female gender, infection with hepatitis B or C virus and malnutrition $[38,39]$.

\subsection{Hepatitis $C$}

Hepatitis $\mathrm{C}$ virus (HCV) is an infectious disease that primarily affects the liver, causing acute or chronic hepatitis [40]. The World Health Organization (2018) estimates a global prevalence of infection by hepatitis $C$ virus of 150 million patients, with 4 million new cases this year. Reports also estimate 500,000 deaths annually by HCV, with Europe, Africa and the eastern Mediterranean being the places with more prevalence $(1.5 \%$ to $2.3 \%)$ [41,42]. In the rest of the world, the prevalence is $1 \%$ approximately. The form of transmission of $\mathrm{HCV}$ is through direct exposure to infected blood as in the case of blood transfusions contaminated with the virus, use of syringes of injecting drug users, use of equipment or medical material without adequate sterilization.

The least frequent forms are sexual transmission and mother-to-child transmission during childbirth. During acute infection, spontaneous healing is infrequent, between 75 and $85 \%$ will develop chronic infection. $50 \%$ to $85 \%$ of patients with the virus will be asymptomatic. Chronic hepatitis $C$ is a slowly progressive disease which causes persistent inflammation, $20 \%$ will progress to cirrhosis in 20 to 30 years [43]. Once it has advanced to the cirrhotic phase, evolution is unpredictable; for many years it can remain indolent until developing some complication of the disease [44]. There is an annual risk of 1 to $6 \%$ of progressing to hepatocellular carcinoma and $3-6 \%$ of presenting with hepatic decompensation [45].

There is currently no vaccine against $\mathrm{HCV}$, but there is a treatment with direct-acting antivirals reaching cure rates exceeding $95 \%$. The treatment cost is very high, so its access in developing countries is still restricted or non-existent [46].

\subsection{Hepatitis $B$}

Hepatitis B virus (HBV) is an infectious disease that causes conditions ranging from anicteric hepatitis to life-threatening conditions such as fulminant hepatitis, or a chronic condition that is characterized by constant inflammation which can progress to cirrhosis or hepatocellular carcinoma [47]. Worldwide, approximately 250 million people have an infection with chronic HBV. Among the regions with the highest prevalence of $\mathrm{HBV}$, with around $10 \%$, are China, Brazil, Southeast Asia, and Africa [48].

According to WHO data from 2018, 4 million new cases of acute HBV hepatitis are detected annually, and about 1 million people die with hepatic cirrhosis related to this infection [49]. In countries with high prevalence between 70 to $90 \%$ of the population contracts the virus at early ages, under 40 years old. If they are infants or children under 5 years $90 \%$, they will present with 
chronic infection. Conversely, in adults, only $5 \%$ will persist chronically with the infection. Of the patients with chronic hepatitis B, 15 to $30 \%$ progresses to liver cirrhosis, and $6 \%$ will develop hepatocellular carcinoma in up to 5 years [50].

HBV is transmitted by direct contact with blood or liquids of body parts such as saliva, semen and vaginal secretions of infected people. It can occur through the use of non-sterile material (needles, syringes, instruments surgical), sexually or perinatally or vertically [51]. Hepatitis B vaccination is available and is safe and prevents chronic hepatitis B. HBV infection in the acute phase does not need treatment. Treatment during the acute phase is only supportive and in case of evolving to chronic phase, treatment with antivirals have been shown to improve survival to prevent the progression of the disease, the risk of decompensation and the development of hepatocellular carcinoma [52].

\subsection{Non-alcoholic fatty liver disease}

Non-alcoholic fatty liver disease (NAFLD) is a chronic pathology that includes benign conditions from simple steatosis, which has no impact on morbidity or short-term mortality until a more serious condition such as non-alcoholic steatohepatitis, that is fat accompanied by inflammatory infiltrate with different degrees of fibrosis, which has the risk of progressing to liver cirrhosis in 3 to $8 \%$ of cases over the course of 5 years [53]. It is defined by the accumulation of fat in the liver that exceeds $5 \%$ of its weight with the presence of cytoplasmic drops of triglycerides in the hepatocytes [54].

NAFLD is linked to obesity and diabetes. According to current data, in the world, there are about 1.46 billion obese adults. In the United States, 6 million of people have nonalcoholic steatohepatitis (NASH), and 600,000 people have cirrhosis due to this etiology [55]. At present, there is no approved pharmacological treatment for NAFLD. But changes in lifestyle are recommended to reverse its evolution [56,57].

\subsection{Autoimmune diseases}

They represent less than $5 \%$ of the etiologies of cirrhosis, including autoimmune hepatitis, primary biliary cholangitis, and primary sclerosing cholangitis

\subsubsection{Autoimmune hepatitis}

It is the chronic inflammation of the liver that is characterized by the presence of elevated levels of gamma globulins, autoantibodies and hepatitis interface in the histopathological study [58]. In the United States and Europe, the prevalence is estimated between 0.1 to 1.2 cases per 100,000 inhabitants. It is responsible for about $6 \%$ of all hepatic transplants, and $80 \%$ of those affected are women. It is potentially fatal without treatment, and almost $50 \%$ of patients die in approximately 5 years, and almost all patients will die within 10 years of the start of the disease [59].

The treatment is based on the use of immunosuppressive therapy with corticosteroids and azathioprine, which has been shown to significantly improve survival rates, reaching $89 \%$ and $90 \%$ survival respectively after 10 years of treatment in patients with and without cirrhosis [60].

\subsubsection{Primary sclerosing cholangitis (PSC)}

It is a chronic disease of unknown etiology that is characterized by an inflammatory reaction and progressive fibrosis of intrahepatic and extrahepatic bile ducts [61]. In Europe and the United States, the prevalence is approximately 6.3 cases per 100,000 inhabitants. $70 \%$ of affected individuals are men with an age of 40 years. Survival from diagnosis is 12 years approximately [62]. It is closely 
related to inflammatory bowel disease since about 70 to $90 \%$ of patients with PSC suffer from it. There is no curative treatment but the management consist of symptomatic treatment and management of complications in case of liver cirrhosis. Liver transplantation is the only treatment that has been shown to improve survival [63].

\subsubsection{Primary Biliary Cholangitis}

It is a progressive autoimmune liver disease that leads to cholestasis and often cirrhosis. Histologically, destruction is observed in small and medium-sized intrahepatic bile ducts. It leads to disorders of biliary excretion and fibrosis [64]. In addition, the characteristic presence of antimitochondrial antibodies has been demonstrated. It occurs more frequently in women between the fourth and the sixth decade of life. The progression of the disease is relatively slow [65]. Between 40 to $68 \%$ of patients will present with fatigue and cholestasis within 5 to 7 years from the onset of the disease. Survival is 7 years for symptomatic patients, and in asymptomatic it is up to 16 years since the diagnosis due to the development of cirrhosis and its complications. Liver transplantation is the only treatment with curative intent. The acid ursodeoxycholic is the main drug used to delay the progression of the disease and delay the need for transplantation [66].

\subsection{Cryptogenic cirrhosis}

Cryptogenic cirrhosis is a diagnosis of exclusion of the chronic liver disease whose etiology could not be determined after performing all the clinical, laboratory and/or histological studies [67]. Viral causes, alcohol, autoimmunity, drugs, genetic causes or disease of the biliary tract must be excluded. It is now known that most of the cases are due to NAFLD. In cirrhotic patients from $3 \%$ to $31 \%$ are of cryptogenic cause and this represents up to $14 \%$ of liver transplants [68].

\subsection{Other causes}

Other causes are infrequent, seen in less than $5 \%$ of patients as cardiac conditions, drugs, genetic diseases such as hemochromatosis, Wilson's disease, and alpha 1 antitrypsin deficit [69,70].

\section{Diagnosis}

Liver cirrhosis is a silent disease, and most patients remain asymptomatic until there is the development of the decompensated phase. Clinical suspicion in most cases is due to an incidental finding of stigmas of chronic liver disease in the physical examination, alteration of the hepatogram in a laboratory analytical control, or when there is decompensation of cirrhosis during a surgical procedure (laparotomy or laparoscopy) indicated by another reason [71].

The evaluation of a patient with suspected cirrhosis should be done in phases starting with a detailed clinical history in which risk factors are identified, An adequate physical examination looking for stigmas of chronic liver disease and finalized with imaging, laboratory and/or histopathological studies that allow to confirm the diagnosis and establish the etiology, in addition to establishing the severity through the different prognostic scales [2].

\subsection{History and Physical Exam}

The majority of patients with liver cirrhosis are usually asymptomatic or have nonspecific symptoms such as asthenia, weight loss, decreased lividness, among others, which delays the diagnosis. When the patient reaches the decompensated phase, symptoms vary from abdominal distention due to ascites and hepatomegaly, hematemesis and melena due to gastrointestinal hemorrhage, alteration of the mental state in hepatic encephalopathy, hypoxemia in case of hydrothorax or hepatopulmonary syndrome, and/or jaundice, symptoms and signs that make you suspect hepatic disease [18]. 
It is important to investigate personal history in search of pathologies which predispose to cirrhosis such as the presence of metabolic syndrome and autoimmune disorders. You must examine risk factors through a detailed history with focus on the personal and social history of alcohol consumption. Factors associated with hepatitis B and C infection (use of injectable drugs, unprotected sex, tattoos, blood transfusions, vaccination), use of hepatotoxic and/or herbal medication, family history of diseases that have a genetic predisposition such as hemochromatosis, Wilson's disease and alpha-1 antitrypsin deficiency should also be considered in the history taking [18].

In the physical examination you can find a variety of manifestations whose presence should make us suspect the disease: asterixis, ascites, collateral abdominal circulation "jellyfish head", spider veins and telangiectasias, palmar erythema, changes in the nails (nail streaks and reddening of the distal third of the nails), Dupuytren's contracture, gynecomastia, hepatomegaly, splenomegaly, bruising, testicular atrophy and jaundice [69].

\subsection{Laboratory tests}

No laboratory test can diagnose liver cirrhosis with accuracy since they do not adequately reflect the operation of the liver by themselves. The diagnosis is achieved by associating the laboratory analyzes with clinical and imaging studies. When suspected liver pathology is identified, a complete hepatic profile consisting of blood biochemistry should be performed with platelet count, prothrombin time, transaminases, bilirubin, alkaline phosphatase, gamma-glutamyltransferase (GGT) and albumin [72].

The alteration of the serum glutamic oxaloacetic transaminase (SGOT) and Glutamic-pyruvic transaminase (SGPT) indicate hepatocellular damage and in cirrhosis are usually high, although they can also be found within values normal. SGOT/SGPT ratio greater than 1 is a strong predictor of cirrhosis except in alcoholic liver disease, and in advanced stages, the relationship may be inverse [73].

Alkaline phosphatase and Gamma-glutamyl transferase (GGT) are enzymes of cholestasis have little diagnostic value. Its elevation suggests primary biliary cholangitis or primary sclerosing cholangitis when other obstructive biliary tract pathologies have been ruled out. When the GGT rises in isolation, it suggests active enzymatic induction by certain drugs [74].

Bilirubin values are usually normal in the compensated state but when the disease progresses they gradually rise, so it is considered an essential parameter for assessing liver function in the Child-Pugh [72]. Albumin is produced exclusively by the liver; therefore, it is a marker which indicates hepatic synthesis dysfunction [75]. The liver synthesizes several coagulation factors that intervene in the extrinsic pathway of coagulation. When the prothrombin time is prolonged, it reflects an alteration of hepatic synthesis [76].

Hyponatremia is a common finding in cirrhotic patients with ascites, by retention of sodium and water by the kidney, and is considered a finding of poor prognosis $[77,78]$. Anemia is caused by several factors such as folic acid deficiency, alcohol toxicity, chronic blood loss and/or hypersplenism [77]. Thrombocytopenia with a count of fewer than 150,000 platelets per $\mathrm{mm} 3$ is a result of the destruction of the platelets due to portal hypertension with hypersplenism and is a sensitive and specific finding for the diagnosis of portal hypertension $[77,78]$.

Leukopenia is caused by portal hypertension with hypersplenism [77]. It is important to remember that the values of the hepatogram can also be altered in pathologies other than the liver. For example, bilirubin in cases of hemolysis, transaminases in thyroid, muscle and cardiac diseases, alkaline phosphatase in bone pathologies [79]. 


\subsection{Imaging studies.}

There is no sufficiently sensitive imaging study to be used as the only method of the diagnosis of cirrhosis. The methods used are:

\subsubsection{Abdominal ultrasound with Doppler.}

It is the diagnostic method of choice because of its low cost, non-invasive and easy access. It has a $91.1 \%$ sensitivity and $93.5 \%$ specificity for the diagnosis of liver cirrhosis. It allows evaluating the macroscopic appearance of the liver, the blood flow of the portal vein and hepatic veins. It can even detect ascites, and with the Doppler, it can help discover signs of portal hypertension. Findings of nodularity, hypertrophy of the caudate lobe, increased echogenicity and parenchymal atrophy are sonographic signs of cirrhosis [80,81].

\subsubsection{Hepatic elastography.}

It is an imaging method that allows measuring the hardness and rigidity of tissue according to the speed of propagation of sound waves [82]. Through this technique, it can estimate the degree of fibrosis in its different stages with a correlation of 83\% with biopsy. In stages 2 (F2) and 3 (F3) of fibrosis, the sensitivity is $84.7 \%$ and $78.3 \%$, with a specificity of $92 \%$ and $81 \%$ respectively. And in stage F4 (advanced fibrosis) reaches a sensitivity of $91.2 \%$, with a specificity of $80 \%[83,84]$.

\subsubsection{Computed tomography and magnetic resonance.}

They are imaging studies of little use for the detection of fibrosis in the initial phase. In advanced stages of the disease, they allow detecting morphological changes such as nodularity, atrophy, hypertrophy of the caudate lobe, ascites and varicose veins. These are not methods of choice due to its high cost and high radiation exposure in the case of the computed tomography. Its current utility lies in the diagnosis of hepatocellular carcinoma $[83,85,86]$.

\subsubsection{Hepatic Biopsy}

It is the gold standard for diagnosing cirrhosis. Its sensitivity and Specificity vary from 80 to 100 percent. However, it is an invasive technique with high cost and with the risk of complications which include pain, mild to massive hemorrhage, peritonitis, sepsis and/or perforation of nearby organs reaching approximate mortality of 1 per 10,000 procedures [87]. It should only be reserved for cases in which the clinical, laboratory and radiological findings do not lead to a diagnosis when it has not been possible to determine the etiology and the results obtained will change the patient's management. It can be done via percutaneous, laparoscopic, surgical or transjugular approach $[88,89]$.

\section{Conclusions}

It is very important to conduct a full prospective study of the etiology of liver cirrhosis and its clinical history, since with treatment and/or withdrawal of the stimuli can slow the progression of the disease and maintain it in compensated stage for more time improving its survival. We suggest the implementation of multidisciplinary work groups in both the primary care as well as for diagnostic evaluation from initial stages and close monitoring of the pathology. Because the prevalence of non-alcoholic steatohepatitis has increased since the last few years, it is important to insist that every individual must be control his metabolic risk factors for a timely correction of them before cardiovascular or hepatic diseases occur. We believe that health policies should be strengthened and prevention campaigns from early ages should be undertaken. 
Author Contributions: All authors contributed equally in this research.

Funding: This research received no external funding.

Acknowledgments: None

Conflicts of Interest: The authors declare no conflict of interest.

\section{References}

1. Zhou, W.C.; Zhang, Q.B.; Qiao, L. Pathogenesis of liver cirrhosis. World journal of gastroenterology 2014, 20, 7312-7324, doi:10.3748/wjg.v20.i23.7312.

2. Wiegand, J.; Berg, T. The etiology, diagnosis and prevention of liver cirrhosis: part 1 of a series on liver cirrhosis. Deutsches Arzteblatt international 2013, 110, 85-91, doi:10.3238/arztebl.2013.0085.

3. Asrani, S.K.; Devarbhavi, H.; Eaton, J.; Kamath, P.S. Burden of liver diseases in the world. Journal of hepatology 2019, 70, 151-171, doi:10.1016/j.jhep.2018.09.014.

4. Marcellin, P.; Kutala, B.K. Liver diseases: A major, neglected global public health problem requiring urgent actions and large-scale screening. Liver international : official journal of the International Association for the Study of the Liver 2018, 38 Suppl 1, 2-6, doi:10.1111/liv.13682.

5. Rowe, I.A. Lessons from Epidemiology: The Burden of Liver Disease. Digestive diseases 2017, 35, 304309, doi:10.1159/000456580.

6. Poordad, F.F. Presentation and complications associated with cirrhosis of the liver. Current medical research and opinion 2015, 31, 925-937, doi:10.1185/03007995.2015.1021905.

7. Pimpin, L.; Cortez-Pinto, H.; Negro, F.; Corbould, E.; Lazarus, J.V.; Webber, L.; Sheron, N.; Committee, E.H.S. Burden of liver disease in Europe: Epidemiology and analysis of risk factors to identify prevention policies. Journal of hepatology 2018, 69, 718-735, doi:10.1016/j.jhep.2018.05.011.

8. Collaboration, G.B.o.D.L.C. The Burden of Primary Liver Cancer and Underlying Etiologies From 1990 to 2015 at the Global, Regional, and National Level: Results From the Global Burden of Disease Study 2015The Global Burden of Liver Cancer 2015The Global Burden of Liver Cancer 2015. JAMA Oncology 2017, 3, 1683-1691, doi:10.1001/jamaoncol.2017.3055.

9. Rawla, P.; Sunkara, T.; Muralidharan, P.; Raj, J.P. Update in global trends and aetiology of hepatocellular carcinoma. Contemporary oncology 2018, 22, 141-150, doi:10.5114/wo.2018.78941.

10. Wong, M.C.S.; Huang, J. The growing burden of liver cirrhosis: implications for preventive measures. Hepatology international 2018, 12, 201-203, doi:10.1007/s12072-018-9865-y.

11. Stasi, C.; Silvestri, C.; Voller, F.; Cipriani, F. Epidemiology of Liver Cirrhosis. Journal of clinical and experimental hepatology 2015, 5, 272, doi:10.1016/j.jceh.2015.06.002.

12. Schuppan, D.; Afdhal, N.H. Liver cirrhosis. Lancet (London, England) 2008, 371, 838-851, doi:10.1016/S0140-6736(08)60383-9.

13. Sivanathan, V.; Kittner, J.M.; Sprinzl, M.F.; Weinmann, A.; Koch, S.; Wiltink, J.; Nguyen-Tat, M.; Marquardt, J.U.; Worns, M.A.; Zimmermann, T., et al. [Etiology and complications of liver cirrhosis: data from a German centre]. Deutsche medizinische Wochenschrift (1946) 2014, 139, 1758-1762, doi:10.1055/s-0034-1387240.

14. Nusrat, S.; Khan, M.S.; Fazili, J.; Madhoun, M.F. Cirrhosis and its complications: evidence based treatment. World journal of gastroenterology 2014, 20, 5442-5460, doi:10.3748/wjg.v20.i18.5442.

15. Rahimi, R.S.; Rockey, D.C. Complications of cirrhosis. Current opinion in gastroenterology 2012, 28, 223229, doi:10.1097/MOG.0b013e328351d003.

16. Wittenburg, H.; Tennert, U.; Berg, T. [Complications of liver cirrhosis]. Der Internist 2011, 52, 10611070; quiz 1071-1062, doi:10.1007/s00108-011-2853-0. 
17. Suk, K.T.; Kim, D.J. Staging of liver fibrosis or cirrhosis: The role of hepatic venous pressure gradient measurement. World journal of hepatology 2015, 7, 607-615, doi:10.4254/wjh.v7.i3.607.

18. Tsochatzis, E.A.; Bosch, J.; Burroughs, A.K. Liver cirrhosis. Lancet 2014, 383, 1749-1761, doi:10.1016/s0140-6736(14)60121-5.

19. Piano, S.; Singh, V.; Caraceni, P.; Maiwall, R.; Alessandria, C.; Fernandez, J.; Soares, E.C.; Kim, D.J.; Kim, S.E.; Marino, M. Epidemiology and effects of bacterial infections in patients with cirrhosis worldwide. Gastroenterology 2018.

20. Mohammed, S.E.A.; Abdo, A.E.; Mudawi, H.M.Y. Mortality and rebleeding following variceal haemorrhage in liver cirrhosis and periportal fibrosis. World journal of hepatology 2016, 8, 1336-1342, doi:10.4254/wjh.v8.i31.1336.

21. Romcea, A.; Tanțău, M.; Seicean, A.; Pascu, O. Variceal bleeding in cirrhotic patients: risk factors, evolution, treatment. Clujul medical (1957) 2013, 86, 107-110.

22. Bajaj, J.S.; O'Leary, J.G.; Tandon, P.; Wong, F.; Garcia-Tsao, G.; Kamath, P.S.; Maliakkal, B.; Biggins, S.W.; Thuluvath, P.J.; Fallon, M.B., et al. Hepatic Encephalopathy Is Associated With Mortality in Patients With Cirrhosis Independent of Other Extrahepatic Organ Failures. Clinical gastroenterology and hepatology : the official clinical practice journal of the American Gastroenterological Association 2017, 15, 565-574.e564, doi:10.1016/j.cgh.2016.09.157.

23. Rawla, P.; Thandra, K.C.; Vellipuram, A.; Ali, C.D.M. Efficacy and safety of megestrol in the management of hepatocellular carcinoma: a systematic review of the literature. Contemporary oncology 2018, 22, 209-214, doi:10.5114/wo.2018.82641.

24. Bustamante, J.; Rimola, A.; Ventura, P.J.; Navasa, M.; Cirera, I.; Reggiardo, V.; Rodes, J. Prognostic significance of hepatic encephalopathy in patients with cirrhosis. Journal of hepatology 1999, 30, 890895.

25. Suraweera, D.; Konyn, P.; Vu, T.; Saab, S. Clinical Epidemiology of Chronic Liver Disease: Hepatocellular Carcinoma. In Clinical Epidemiology of Chronic Liver Diseases, Springer: 2019; pp. 229249.

26. Petrick, J.L.; Kelly, S.P.; Altekruse, S.F.; McGlynn, K.A.; Rosenberg, P.S. Future of hepatocellular carcinoma incidence in the United States forecast through 2030. Journal of Clinical Oncology 2016, 34, 1787.

27. White, D.L.; Thrift, A.P.; Kanwal, F.; Davila, J.; El-Serag, H.B. Incidence of hepatocellular carcinoma in all 50 United States, from 2000 through 2012. Gastroenterology 2017, 152, 812-820. e815.

28. Byass, P. The global burden of liver disease: a challenge for methods and for public health. BMC medicine 2014, 12, 159-159, doi:10.1186/s12916-014-0159-5.

29. Angeli, P.; Ginès, P.; Wong, F.; Bernardi, M.; Boyer, T.D.; Gerbes, A.; Moreau, R.; Jalan, R.; Sarin, S.K.; Piano, S., et al. Diagnosis and management of acute kidney injury in patients with cirrhosis: Revised consensus recommendations of the International Club of Ascites. Journal of hepatology 2015, 62, 968974, doi:10.1016/j.jhep.2014.12.029.

30. Poynard, T.; Mathurin, P.; Lai, C.L.; Guyader, D.; Poupon, R.; Tainturier, M.H.; Myers, R.P.; Muntenau, M.; Ratziu, V.; Manns, M., et al. A comparison of fibrosis progression in chronic liver diseases. Journal of hepatology 2003, 38, 257-265.

31. Sun, M.; Kisseleva, T. Reversibility of liver fibrosis. Clinics and research in hepatology and gastroenterology 2015, 39 Suppl 1, S60-63, doi:10.1016/j.clinre.2015.06.015.

32. Friedman, S.L. Evolving challenges in hepatic fibrosis. Nature reviews. Gastroenterology $\mathcal{E}$ hepatology 2010, 7, 425-436, doi:10.1038/nrgastro.2010.97. 
33. Benyon, R.C.; Arthur, M.J.P. Extracellular Matrix Degradation and the Role of Hepatic Stellate Cells. Semin Liver Dis 2001, 21, 373-384, doi:10.1055/s-2001-17552.

34. Horvat, T.; Landesmann, B.; Lostia, A.; Vinken, M.; Munn, S.; Whelan, M. Adverse outcome pathway development from protein alkylation to liver fibrosis. Archives of toxicology 2017, 91, 1523-1543, doi:10.1007/s00204-016-1814-8.

35. Bruha, R.; Dvorak, K.; Petrtyl, J. Alcoholic liver disease. World journal of hepatology 2012, 4, 81-90, doi:10.4254/wjh.v4.i3.81.

36. Askgaard, G.; Gronbaek, M.; Kjaer, M.S.; Tjonneland, A.; Tolstrup, J.S. Alcohol drinking pattern and risk of alcoholic liver cirrhosis: a prospective cohort study. Journal of hepatology 2015, 62, 1061-1067, doi:10.1016/j.jhep.2014.12.005.

37. Osna, N.A.; Donohue, T.M., Jr.; Kharbanda, K.K. Alcoholic Liver Disease: Pathogenesis and Current Management. Alcohol research : current reviews 2017, 38, 147-161.

38. Hagström, H. Alcohol Consumption in Concomitant Liver Disease: How Much is Too Much? Current hepatology reports 2017, 16, 152-157, doi:10.1007/s11901-017-0343-0.

39. Whitfield, J.B.; Masson, S.; Liangpunsakul, S.; Hyman, J.; Mueller, S.; Aithal, G.; Eyer, F.; Gleeson, D.; Thompson, A.; Stickel, F. Evaluation of laboratory tests for cirrhosis and for alcohol use, in the context of alcoholic cirrhosis. Alcohol 2018, 66, 1-7.

40. Scaglione, S.; Kliethermes, S.; Cao, G.; Shoham, D.; Durazo, R.; Luke, A.; Volk, M.L. The epidemiology of cirrhosis in the United States. Journal of clinical gastroenterology 2015, 49, 690-696.

41. El-Serag, H.; Kramer, J.; Duan, Z.; Kanwal, F. Epidemiology and outcomes of hepatitis C infection in elderly US Veterans. Journal of viral hepatitis 2016, 23, 687-696.

42. Thrift, A.P.; El-Serag, H.B.; Kanwal, F. Global epidemiology and burden of HCV infection and HCVrelated disease. Nature reviews Gastroenterology E hepatology 2017, 14, 122.

43. van der Meer, A.J.; Feld, J.J.; Hofer, H.; Almasio, P.L.; Calvaruso, V.; Fernández-Rodríguez, C.M.; Aleman, S.; Ganne-Carrié, N.; D’Ambrosio, R.; Pol, S. Risk of cirrhosis-related complications in patients with advanced fibrosis following hepatitis C virus eradication. Journal of hepatology 2017, 66, 485-493.

44. Rüeger, S.; Bochud, P.; Dufour, J.-F.; Müllhaupt, B.; Semela, D.; Heim, M.; Moradpour, D.; Cerny, A.; Malinverni, R.; Booth, D. Impact of common risk factors of fibrosis progression in chronic hepatitis C. Gut 2015, 64, 1605-1615.

45. Millman, A.J.; Nelson, N.P.; Vellozzi, C. Hepatitis C: Review of the Epidemiology, Clinical Care, and Continued Challenges in the Direct-Acting Antiviral Era. Current epidemiology reports 2017, 4, 174-185.

46. EASL Recommendations on Treatment of Hepatitis C 2018. Journal of hepatology 2018, 69, 461-511, doi:10.1016/j.jhep.2018.03.026.

47. Terrault, N.A.; Bzowej, N.H.; Chang, K.M.; Hwang, J.P.; Jonas, M.M.; Murad, M.H. A ASLD guidelines for treatment of chronic hepatitis B. Hepatology 2016, 63, 261-283.

48. Schweitzer, A.; Horn, J.; Mikolajczyk, R.T.; Krause, G.; Ott, J.J. Estimations of worldwide prevalence of chronic hepatitis B virus infection: a systematic review of data published between 1965 and 2013. The Lancet 2015, 386, 1546-1555.

49. Lavanchy, D.; Kane, M. Global epidemiology of hepatitis B virus infection. In Hepatitis B virus in human diseases, Springer: 2016; pp. 187-203.

50. Bogler, Y.; Wong, R.J.; Gish, R.G. Epidemiology and Natural History of Chronic Hepatitis B Virus Infection. In Hepatitis B Virus and Liver Disease, Springer: 2018; pp. 63-89. 
51. Nannini, P.; Sokal, E.M. Hepatitis B: changing epidemiology and interventions. Archives of disease in childhood 2017, 102, 676-680.

52. Nelson, N.P.; Easterbrook, P.J.; McMahon, B.J. Epidemiology of hepatitis B virus infection and impact of vaccination on disease. Clinics in liver disease 2016, 20, 607-628.

53. Zhang, X.J.; She, Z.G.; Li, H. Time to step-up the fight against NAFLD. Hepatology 2018, 67, $2068-2071$.

54. Buzzetti, E.; Pinzani, M.; Tsochatzis, E.A. The multiple-hit pathogenesis of non-alcoholic fatty liver disease (NAFLD). Metabolism 2016, 65, 1038-1048.

55. Dowman, J.K.; Farrell, G.C.; Newsome, P. NAFLD: A worldwide problem. Clinical Dilemmas in NonAlcoholic Fatty Liver Disease 2016, 20, 8.

56. McPherson, S.; Hardy, T.; Henderson, E.; Burt, A.D.; Day, C.P.; Anstee, Q.M. Evidence of NAFLD progression from steatosis to fibrosing-steatohepatitis using paired biopsies: implications for prognosis and clinical management. Journal of hepatology 2015, 62, 1148-1155.

57. Rinella, M.E.; Sanyal, A.J. Management of NAFLD: a stage-based approach. Nature reviews Gastroenterology \& hepatology 2016, 13, 196.

58. Liberal, R.; Krawitt, E.L.; Vierling, J.M.; Manns, M.P.; Mieli-Vergani, G.; Vergani, D. Cutting edge issues in autoimmune hepatitis. Journal of autoimmunity 2016, 75, 6-19.

59. Czaja, A.J. Global disparities and their implications in the occurrence and outcome of autoimmune hepatitis. Digestive diseases and sciences 2017, 62, 2277-2292.

60. Liberal, R.; de Boer, Y.S.; Andrade, R.J.; Bouma, G.; Dalekos, G.N.; Floreani, A.; Gleeson, D.; Hirschfield, G.M.; Invernizzi, P.; Lenzi, M. Expert clinical management of autoimmune hepatitis in the real world. Alimentary pharmacology \& therapeutics 2017, 45, 723-732.

61. Rawla, P.; Samant, H. Primary Sclerosing Cholangitis. In StatPearls, StatPearls Publishing. StatPearls Publishing LLC.: Treasure Island (FL), 2018.

62. Lazaridis, K.N.; LaRusso, N.F. Primary sclerosing cholangitis. New England Journal of Medicine 2016, $375,1161-1170$.

63. Lindor, K.D.; Kowdley, K.V.; Harrison, M.E. ACG clinical guideline: primary sclerosing cholangitis. The American journal of gastroenterology 2015, 110, 646.

64. Carey, E.J.; Ali, A.H.; Lindor, K.D. Primary biliary cirrhosis. The Lancet 2015, 386, 1565-1575.

65. Liver, E.A.f.t.S.o.t. EASL Clinical Practice Guidelines: The diagnosis and management of patients with primary biliary cholangitis. Journal of hepatology 2017, 67, 145-172.

66. Hirschfield, G.M.; Dyson, J.K.; Alexander, G.J.; Chapman, M.H.; Collier, J.; Hübscher, S.; Patanwala, I.; Pereira, S.P.; Thain, C.; Thorburn, D. The British Society of Gastroenterology/UK-PBC primary biliary cholangitis treatment and management guidelines. Gut 2018, 67, 1568-1594.

67. Thuluvath, P.J.; Kantsevoy, S.; Thuluvath, A.J.; Savva, Y. Is cryptogenic cirrhosis different from NASH cirrhosis? Journal of hepatology 2018, 68, 519-525.

68. Henry, Z.; Argo, C.K.; Caldwell, S.H. Cryptogenic Cirrhosis. In Clinical Epidemiology of Chronic Liver Diseases, Springer: 2019; pp. 331-349.

69. Schuppan, D.; Afdhal, N.H. Liver cirrhosis. Lancet 2008, 371, 838-851, doi:10.1016/s01406736(08)60383-9.

70. Porter, J.L.; Rawla, P. Hemochromatosis. In StatPearls, StatPearls Publishing. StatPearls Publishing LLC.: Treasure Island (FL), 2018. 
71. Fukui, H.; Saito, H.; Ueno, Y.; Uto, H.; Obara, K.; Sakaida, I.; Shibuya, A.; Seike, M.; Nagoshi, S.; Segawa, M. Evidence-based clinical practice guidelines for liver cirrhosis 2015. Journal of gastroenterology 2016, 51, 629-650.

72. Ahmed, Z.; Ahmed, U.; Walayat, S.; Ren, J.; Martin, D.K.; Moole, H.; Koppe, S.; Yong, S.; Dhillon, S. Liver function tests in identifying patients with liver disease. Clinical and experimental gastroenterology 2018, 11, 301-307, doi:10.2147/CEG.S160537.

73. Giannini, E.G.; Testa, R.; Savarino, V. Liver enzyme alteration: a guide for clinicians. CMAJ : Canadian Medical Association journal = journal de l'Association medicale canadienne 2005, 172, 367-379, doi:10.1503/cmaj.1040752.

74. McLernon, D.J.; Donnan, P.T.; Sullivan, F.M.; Roderick, P.; Rosenberg, W.M.; Ryder, S.D.; Dillon, J.F. Prediction of liver disease in patients whose liver function tests have been checked in primary care: model development and validation using population-based observational cohorts. BMJ open 2014, 4, e004837-e004837, doi:10.1136/bmjopen-2014-004837.

75. Walayat, S.; Martin, D.; Patel, J.; Ahmed, U.; N Asghar, M.; Pai, A.U.; Dhillon, S. Role of albumin in cirrhosis: from a hospitalist's perspective. Journal of community hospital internal medicine perspectives 2017, 7, 8-14, doi:10.1080/20009666.2017.1302704.

76. Blasi, A. Coagulopathy in liver disease: Lack of an assessment tool. World journal of gastroenterology 2015, 21, 10062-10071, doi:10.3748/wjg.v21.i35.10062.

77. Marks, P.W. Hematologic manifestations of liver disease. Seminars in hematology 2013, 50, 216-221, doi:10.1053/j.seminhematol.2013.06.003.

78. Qamar, A.A.; Grace, N.D. Abnormal hematological indices in cirrhosis. Canadian journal of gastroenterology = Journal canadien de gastroenterologie 2009, 23, 441-445.

79. Newsome, P.N.; Cramb, R.; Davison, S.M.; Dillon, J.F.; Foulerton, M.; Godfrey, E.M.; Hall, R.; Harrower, U.; Hudson, M.; Langford, A., et al. Guidelines on the management of abnormal liver blood tests. Gut 2018, 67, 6, doi:10.1136/gutjnl-2017-314924.

80. Kelly, E.M.M.; Feldstein, V.A.; Parks, M.; Hudock, R.; Etheridge, D.; Peters, M.G. An Assessment of the Clinical Accuracy of Ultrasound in Diagnosing Cirrhosis in the Absence of Portal Hypertension. Gastroenterology E hepatology 2018, 14, 367-373.

81. Procopet, B.; Berzigotti, A. Diagnosis of cirrhosis and portal hypertension: imaging, non-invasive markers of fibrosis and liver biopsy. Gastroenterology report 2017, 5, 79-89, doi:10.1093/gastro/gox012.

82. Gherlan, G.S. Liver ultrasound elastography: More than staging the disease. World journal of hepatology 2015, 7, 1595-1600, doi:10.4254/wjh.v7.i12.1595.

83. Srinivasa Babu, A.; Wells, M.L.; Teytelboym, O.M.; Mackey, J.E.; Miller, F.H.; Yeh, B.M.; Ehman, R.L.; Venkatesh, S.K. Elastography in Chronic Liver Disease: Modalities, Techniques, Limitations, and Future Directions. Radiographics : a review publication of the Radiological Society of North America, Inc 2016, 36, 1987-2006, doi:10.1148/rg.2016160042.

84. Song, J.E.; Lee, D.W.; Kim, E.Y. Endoscopic Ultrasound Real-Time Elastography in Liver Disease. Clinical endoscopy 2018, 51, 118-119, doi:10.5946/ce.2018.049.

85. Lertpipopmetha, K.; Tubtawee, T.; Piratvisuth, T.; Chamroonkul, N. Comparison between Computer Tomography and Magnetic Resonance Imaging in the Diagnosis of Small Hepatocellular Carcinoma. Asian Pacific journal of cancer prevention : APJCP 17, 4805-4811, doi:10.22034/APJCP.2016.17.11.4805. 
86. de Ledinghen, V.; Laharie, D.; Lecesne, R.; Le Bail, B.; Winnock, M.; Bernard, P.H.; Saric, J.; Couzigou, P.; Balabaud, C.; Bioulac-Sage, P., et al. Detection of nodules in liver cirrhosis: spiral computed tomography or magnetic resonance imaging? A prospective study of 88 nodules in 34 patients. European journal of gastroenterology \& hepatology 2002, 14, 159-165.

87. Thampanitchawong, P.; Piratvisuth, T. Liver biopsy:complications and risk factors. World journal of gastroenterology 1999, 5, 301-304, doi:10.3748/wjg.v5.i4.301.

88. Germani, G.; Hytiroglou, P.; Fotiadu, A.; Burroughs, A.K.; Dhillon, A.P. Assessment of fibrosis and cirrhosis in liver biopsies: an update. Semin Liver Dis 2011, 31, 82-90, doi:10.1055/s-0031-1272836.

89. Tannapfel, A.; Dienes, H.-P.; Lohse, A.W. The indications for liver biopsy. Deutsches Arzteblatt international 2012, 109, 477-483, doi:10.3238/arztebl.2012.0477. 